\title{
Previous disturbance enhances the negative effects of trampling on barnacles
}

\author{
Jeremy D. Long ${ }^{1, *}$, E. Cochrane ${ }^{2}$, R. E. Dolecal ${ }^{1}$ \\ ${ }^{1}$ Department of Biology \& Coastal Marine Institute Laboratory, San Diego State University, San Diego, California 92182, USA \\ ${ }^{2}$ Maine Maritime Academy, Castine, Maine 04420, USA
}

\begin{abstract}
Communities are influenced by multiple stressors that can interact in surprising ways, yet trampling studies typically ignore other sources of disturbance. While there is some evidence that disturbed communities may resist trampling because of species shifts, we lack an understanding of how previous disturbance interacts with trampling in monospecific stands. Furthermore, recent studies emphasized experimental trampling additions with assumed ecological realism. We monitored barnacle cover in unmanipulated and experimentally disturbed plots at 2 sites separated by only $300 \mathrm{~m}$ and with disparate levels of human visitation. During the summer, barnacle cover increased by 6 and $15 \%$ at the less-visited site but decreased by 5 and $4 \%$ at the heavily visited site (unmanipulated and disturbed plots, respectively). Interestingly, the influence of site on barnacle cover was greater in disturbed than in unmanipulated plots. New recruits represented a greater proportion of the barnacles at the heavily visited site. Neither plot slope nor predator abundance differed between these sites. To isolate the influence of trampling on barnacles, we monitored barnacle cover in caged, human exclusion plots and in uncaged controls at both sites. Summer barnacle cover increased in all treatments except in uncaged plots at the heavily visited site. During 9 paired surveys coinciding with the exclusion experiment, as many as 70 humans $\left(\mathrm{km}^{-1}\right.$ shoreline $\left.\mathrm{h}^{-1}\right)$ entered the intertidal zone of the heavily visited site but no one did so at the less-visited site. Given that (1) visitation was the dominant factor explaining differences in barnacle cover between the 2 sites, and (2) caging enhanced barnacle cover only at the heavily visited site, we conclude that previous disturbance mediated the effects of human trampling on barnacle populations, with more disturbed plots displaying greater trampling vulnerability.
\end{abstract}

KEY WORDS: Multiple stressor effects $\cdot$ Human disturbance $\cdot$ Rocky shore $\cdot$ Intertidal

\section{INTRODUCTION}

Communities are shaped by several abiotic and biotic stressors that often act simultaneously or before the communities have fully recovered from previous disturbance (Pentcheff 1991, Hughes \& Connell 1999, Crain et al. 2008, Hart \& Chen 2008). For example, the influence of disease on the dominant Caribbean sea urchin Diadema, and the cascading effects on macroalgae were contingent upon the severity of overfishing on particular reefs (Hughes et al. 1987, Lessios 1988). However, many studies con- tinue to examine the role of individual stressors independently of each other (but see Smith \& Murray 2005, Hill \& Pickering 2009 for exceptions). Given that multiple stressors regularly interact to disturb communities in unexpected ways (e.g. synergistically), it is imperative that we examine the cumulative effects of multiple stressors (Hughes \& Connell 1999, Crain et al. 2008, Darling \& Cote 2008).

Although human trampling is an important source of disturbance for organisms, we lack an understanding of how trampling interacts with other disturbance factors (but see Martone \& Wasson 2008 
for an exception). Previous disturbance may influence trampling resistance via at least 3 mechanisms. First, recently disturbed communities may be less susceptible to trampling because they are dominated by trampling-resistant species that survived the initial disturbance (Liddle 1991, Povey \& Keough 1991, Brosnan 1994, Brown \& Taylor 1999, Hill \& Pickering 2009). For example, disturbed communities dominated by lawn grasses are 2 to $10 \times$ more resistant to trampling than undisturbed communities dominated by ferns or tussock grasses (Yorks et al. 1997, Hill \& Pickering 2009). Second, disturbed populations may contain trampling-resistant genotypes (Warwick \& Briggs 1978). For example, regularly mown bowling greens contained prostrate genotypes of Poa annua while less-disturbed populations contained a mixture of prostrate and erect genotypes (Warwick \& Briggs 1978). Third, disturbed populations may contain phenotypes that are differentially susceptible to trampling, perhaps because of life history differences. For example, populations dominated by young, trampling-susceptible individuals (e.g. recruits or seedlings) may be more susceptible to trampling damage, especially in monospecific stands and areas dominated by a few species. Tests of this third mechanism are lacking.

Barnacles represent one of the best studied taxa with respect to trampling (Zedler 1978, Beauchamp \& Gowing 1982, Povey \& Keough 1991, Brosnan 1994, Jenkins et al. 2002, Ferreira \& Rosso 2009). However, previous barnacle trampling studies ignored other important disturbances (e.g. waves, wrack and ice scour, thermal stress). Studying trampling in isolation from other disturbances may have created some of the uncertainty associated with the influence of trampling on barnacles. For example, footsteps can lower barnacle survivorship (Povey \& Keough 1991) and trampling additions can reduce barnacle cover (Brosnan 1994, Ferreira \& Rosso 2009). However, several studies found no effect of trampling on barnacle cover (Jenkins et al. 2002) or density (Beauchamp \& Gowing 1982, Goldstein 1992). Furthermore, the effects of trampling additions on barnacles can vary even within a study (Zedler 1978). The interaction of disturbance factors could be especially important in barnacle communities where disturbance and recruitment regularly create mosaics of 0 to $100 \%$ barnacle cover across small spatial scales (Wethey 1985).

In addition to examining trampling in isolation from other disturbances, more realistic trampling manipulations are needed. Trampling studies typically compare sites with different levels of existing visitation (i.e. post-impact studies; Beauchamp \& Gowing
1982, Van De Werfhorst \& Pearse 2007) or sites with different levels of trampling applications (i.e. trampling addition studies; Schiel \& Taylor 1999, Jenkins et al. 2002, Smith \& Murray 2005, Casu et al. 2006). Post-impact studies cannot assign causation because their data are correlative (Keough \& Quinn 1991). In contrast, trampling additions allow a test of causality (Keough \& Quinn 1991) but require untested assumptions about the ecological relevance of the trampling addition (e.g. duration and frequency of trampling, behavior and footwear of the trampler). These assumptions warrant further investigation given the well-known importance of disturbance characteristics on community structure (Connell 1978, Sousa 1979, Menge \& Sutherland 1987). Despite the rich history of using cages to examine the ecological consequences of excluding species (Menge 1976, Lubchenco 1983, Menge 1991, Micheli et al. 2002, Navarrete \& Castilla 2003, Vinueza et al. 2006) and the need to establish causal links between human activities and their consequences (Keough \& Quinn 1991), human exclusions are rarely used to study trampling (but see Castilla \& Duran 1985, Godefroid et al. 2003, Casu et al. 2006 for evidence that excluding humans can influence community structure).

We conducted a post-impact study and a human exclusion experiment at 2 sites with known, disparate levels of visitation (i.e. high vs. low visitation) to examine how experimental clearings interacted with trampling to influence barnacle cover. We compared the change in barnacle cover across the peak tourist season in unmanipulated, established plots and in scraped, disturbed plots in the barnacle zone. We hypothesized that previous disturbance would interact with site to influence barnacle cover. To isolate the influence of trampling on barnacles, we protected barnacles from trampling using cages that allowed predator access and compared these to uncaged controls. Finally, we compared other abiotic and biotic factors between these sites to explore alternative explanations for our results.

\section{MATERIALS AND METHODS}

We examined the influence of human trampling on barnacle cover at 2 sites separated by only $\sim 300 \mathrm{~m}$ by a small harbor in Acadia National Park, Mount Desert Island, Maine (Bass Harbor hereafter ' $\mathrm{BH}^{\prime}$ (UTM: 19T 554136, 4897034, NAD 1983) and Ship Harbor hereafter 'SH' (UTM: 19T 554540, 4897113, NAD1983)). The high intertidal zones of these sites are dominated by the barnacle Semibalanus bal- 
anoides. These sites were selected because of their close proximity, and presumably similar abiotic conditions, yet very disparate levels of human visitation. With respect to abiotic factors, both sites are found on the same bedrock formation ('pink, fine grained granite with a distinctive sugary texture' and 'contains abundant veins of coarser quartz and feldspar;' Gilman \& Chapman 1988). Rock type is an important determinant of intertidal community composition (Raimondi 1988, Schoch \& Dethier 1996). Also, the aspect of both sites is generally similar-SouthSoutheast (pers. obs.). In contrast, human visitation differs greatly between these sites. SH receives high levels of visitation during summer months because of a well-maintained, easily travelled park trail. In contrast, $\mathrm{BH}$ receives almost no visitation because it can only be accessed through a moderate-to-difficult social trail. For example, during daily low-tide surveys at BH from June to August 2005, only one group of 3 people entered the intertidal zone (pers. obs.).

As part of a long-term, rocky intertidal monitoring program (Long \& Mitchell 2010), we installed 2 types of fixed plots in the barnacle zone at both sites in April 2008: established plots and disturbed plots ( $\mathrm{N}=$ 5). In established plots, the barnacle community was not manipulated. In disturbed plots, however, the barnacle community was scraped clear on 1 April 2008 (BH) and 3 April 2008 (SH) prior to the major period of barnacle recruitment. Similar clearings naturally occur in barnacle communities via several stressors (e.g. boulder movement and ice scour; pers. obs.). Because of the different pre-treatment of established and disturbed plots, this design allowed for a comparison of the role of previous disturbance (e.g. boulder movement or ice scour), human trampling, and their interaction on barnacle cover. To minimize edge effects, we initially scraped all organisms within $7 \mathrm{~cm}$ outside of all plots (established and disturbed).

Plot locations were selected based on optimal conditions for long-term monitoring including reasonable and safe access and sufficient abundances of barnacles. Additionally, we modeled our approach after the Multi-Agency Rocky Intertidal Network's (MARINe) monitoring program, and thus selected nearly flat, horizontal plots (Engle 2006). Consequently, our results represent horizontal areas where trampling should have the strongest effect (i.e. we don't expect humans to trample vertical walls). To select the 5 replicates for each plot type at each site, 10 quadrats were haphazardly placed in each target species zone for each plot type. These 10 quadrats were placed at least $50 \mathrm{~cm}$ apart to facilitate plot relocation using a single reference bolt. From these 10 quadrats, 5 were randomly selected as the final plot locations.

Established plots measured $50 \times 75 \mathrm{~cm}$ and disturbed plots were $20 \times 20 \mathrm{~cm}$. The size of established plots was selected to match the plot size used by the MARINe monitoring program. The smaller size of disturbed plots was selected (1) to minimize disturbance to natural resources within the National Park, and (2) because similar-sized plots have been used to monitor intertidal cover in New England (Altieri et al. 2009). It is unlikely that this difference in plot size led to differential trampling between plot types.

All plots were marked with stainless steel hex bolts extending $2.5 \mathrm{~cm}$ above the substrate and anchored into the bedrock. Established plots were marked with a bolt at each corner while disturbed plots only had bolts at 2 diagonal corners. In rocky intertidal areas, the well-known spatial heterogeneity in the distribution and abundance of intertidal organisms means that randomly placing plots each year (as opposed to using fixed plots) would make it harder to detect temporal trends, because the exact placement of plots strongly affects the number of individuals present within them. Using fixed plots allows us to detect temporal trends with fewer plots, although this has the drawback of precluding extrapolation to larger areas without gathering additional information (Engle 2006, Murray et al. 2006).

In 2008, we photographed plots on 21 June (both sites), 2 August (SH), 5 August (BH), and 21 September (both sites). To examine temporal changes across longer periods, we also determined barnacle cover in the established plots in late June 2009. For all dates, we identified the canopy (i.e. top) species or substrate beneath 100 or 200 points for each photograph (for established and disturbed plots, respectively). For disturbed plots, the 200 points were randomly placed within a $10 \times 10 \mathrm{~cm}$ area placed in the center of each plot. We conducted a repeated-measures ANOVA on arcsin square-root transformed percent cover data with site $(\mathrm{BH}, \mathrm{SH})$ and plot type (established, disturbed) as the between subjects factors and transformed percent cover as the repeated measure (June, August, September). Site was selected as a fixed factor because we specifically selected these sites: BH for low visitation and SH for high visitation.

To determine if trampling has longer term effects on barnacle demographics, we compared the sizes of barnacles in established plots at both sites in June 2008. By focusing on plots in June, we were able to compare barnacle sizes independent of that year's major trampling period which occurs during later summer months. All sizes were measured using digi- 
tal photographs and imageJ. First, we determined the maximum size of new recruits at each site by measuring the basal and opercular areas of 10 randomly selected barnacles within each disturbed plot. Because disturbed plots were scraped prior to recruitment, all individuals in these plots were new recruits in June 2008. At each site, basal area was positively correlated with opercular area $\left(\mathrm{BH}, \mathrm{R}^{2}=0.82, \mathrm{p}<\right.$ 0.001 ; $\left.\mathrm{SH}, \mathrm{R}^{2}=0.83, \mathrm{p}<0.001\right)$. Using these site-specific maxima of basal area, we calculated the percentage of barnacles (out of 100 randomly selected individuals) that were below this size in each established plot $(\mathrm{n}=5)$. We compared the 2 sites using a 2-sample, 2-tailed $t$-test on arcsin square-root transformed percentages.

The post-impact study suggested a correlation between human visitation and declining barnacle cover starting early in the summer when seasonal visitation increased dramatically. To better understand this relationship, we conducted a human exclusion experiment to manipulate trampling in previously disturbed plots. We scraped twenty $30 \times 30 \mathrm{~cm}$ clearings in the barnacle zone at both sites in April 2009 (2 and 3 April at $\mathrm{SH}$ and $\mathrm{BH}$, respectively), dates prior to the major barnacle recruitment period. Immediately after scraping the plots, we installed stainless steel cages $(20 \times 20 \times 5 \mathrm{~cm}$; length $\times$ width $\times$ height $)$ over all plots. Cages were reinforced with a PVC spacer around a center bolt. Initially, cages prevented trampling on all plots so that plots would start with similar barnacle cover. On 3 June 2009, we photographed all plots, and randomly assigned half of the plots to the uncaged treatments from which the cages were then removed. Each cage had 2 openings $(10 \times 3 \mathrm{~cm}$ each; length $\times$ height $)$ on opposite walls to allow access by the dominant barnacle predators, dogwhelks and crabs. Thus, differences in barnacle cover between caged and uncaged plots at a given site were not due to differences in barnacle predation because the dominant predators had access to and were observed alive in cages. Uncaged plots were susceptible to trampling, and were marked with an inconspicuous bolt screwed down to the rock surface. Unfortunately, 6 cages were lost during a storm leaving final replication at 10,9, 8, and 7, for $\mathrm{BH}$ caged, $\mathrm{BH}$ uncaged, $\mathrm{SH}$ caged, and $\mathrm{SH}$ uncaged, respectively. The cages remained unfouled for the duration of the experiment. On 27 July 2009, we removed the cages and photographed all plots.

From these photographs, we determined barnacle cover under 200 randomly placed points within each plot at the start and end of the experiment. Points falling within a $2.2 \mathrm{~cm}$ diameter circle around the bolt hole and spacer scar were randomly regenerated until we had 200 points within the plot but outside of this area. We hypothesized that we would observe high barnacle cover in all $\mathrm{BH}$ plots and $\mathrm{SH}$ caged plots, but low barnacle cover in $\mathrm{SH}$ uncaged plots because of trampling. We conducted a repeatedmeasures ANOVA on transformed percent cover data, with site (BH, SH) and caging treatment (caged, uncaged) as the between subjects factors and transformed percent cover as the repeated measure (initial, final).

We compared several biotic (predator abundance and human visitation) and abiotic factors (slope, elevation, and temperature) between these sites that might influence barnacle cover (Menge 1976, Smith \& Murray 2005, Heaven \& Scrosati 2008, Vaselli et al. 2008). Preliminary observations from 2005 to 2008 suggested that more people visit $\mathrm{SH}$ than $\mathrm{BH}$. During the human exclusion experiment, we quantified human visitation at $\mathrm{BH}$ and $\mathrm{SH}$ on $9 \mathrm{~d}$ between 18 June and 17 July. Simultaneous paired surveys were conducted $30 \mathrm{~min}$ before the daytime low tide and lasted $2 \mathrm{~h}$. The same section of shore was surveyed between days. The lengths of these areas were estimated using the shortest linear distance between endpoint landmarks using GPS coordinates. The lengths of areas surveyed for humans were $0.1048 \mathrm{~km}$ in $\mathrm{BH}$ and $0.2706 \mathrm{~km}$ in $\mathrm{SH}$. The difference in length was a result of the location of landmark rocks and line of sight at each site. The greater length in $\mathrm{SH}$ does not indicate that it is bigger than $\mathrm{BH}$, but rather that the area surveyed was longer. However, we corrected for this difference by dividing human sightings by the length of the surveyed area. We only counted people who entered the intertidal zone during surveys.

Spatial variation in barnacle survivorship may be related to predation intensity. For example, the Atlantic dogwhelk Nucella lapillus exerts well-known control of barnacle and mussel prey on New England rocky shores (Menge 1976, Menge \& Sutherland 1976). During the human exclusion experiment, we determined the density of $N$. lapillus in established barnacle plots at BH (22 June 2009) and SH (23 June $2009 ; \mathrm{n}=5$ ). Within the entire $50 \times 75 \mathrm{~cm}$ quadrat, we counted dogwhelks with shell lengths $>7 \mathrm{~mm}$ (a size well below the smallest $N$. lapillus we typically observed). To better understand site-wide variation in $N$. lapillus density, we repeated this procedure in Fucus and Ascophyllum plots that were surveyed as part of our overall monitoring program at both sites (n = 5). Densities of $N$. lapillus were analyzed using ANOVA after $\log (\mathrm{x}+1)$ transformation, with site $(2$ levels: $\mathrm{SH}$ and $\mathrm{BH}$ ) as a random factor and plot type 
(3 levels; Ascophyllum, barnacle, and Fucus) as a fixed factor.

We placed an inclinometer along the dominant slope of each plot to determine plot slope. We measured plot elevation (vertical distance above mean low water) with reference to the still-water level on 21 September 2008. Slope and elevation were each analyzed using separate ANOVAs, with site and plot type (established or disturbed) as fixed factors.

\section{RESULTS}

Despite a similar starting cover in June 2008, barnacle cover was lower in both plot types at the heavily visited $(\mathrm{SH})$ than at the less-visited site $(\mathrm{BH})$ (Fig. 1, Table 1: site effect). Although hummocking was common in both plot types at $\mathrm{BH}$, it was not observed in $\mathrm{SH}$ plots. Barnacle cover also tended to be higher in established than in disturbed plots (Fig. 1, Table 1: plot type effect). From June to September 2008, barnacle cover in established plots increased by $6 \%$ at $\mathrm{BH}$ but decreased by $5 \%$ at $\mathrm{SH}$ (Fig. 1a). Although qualitatively similar, these temporal changes were quantitatively different in disturbed plots, where barnacle cover increased by $15 \%$ at $\mathrm{BH}$ but decreased by $4 \%$ at SH (Fig. 1b, Table 1). Overall, barnacle cover increased through time at $\mathrm{BH}$ but decreased at SH (Fig. 1, Table 1: Time $\times$ Site interaction). However, the interaction between time and site, although qualitatively similar, varied with previous disturbance (Fig. 1, Table 1: Time $\times$ Plot type $\times$ Site interaction). Thus, the differences in the effect of time between the 2 sites depended on previous disturbance, with a greater difference in the previously disturbed plots. We observed significant recovery within the established plots at SH. Despite barnacle

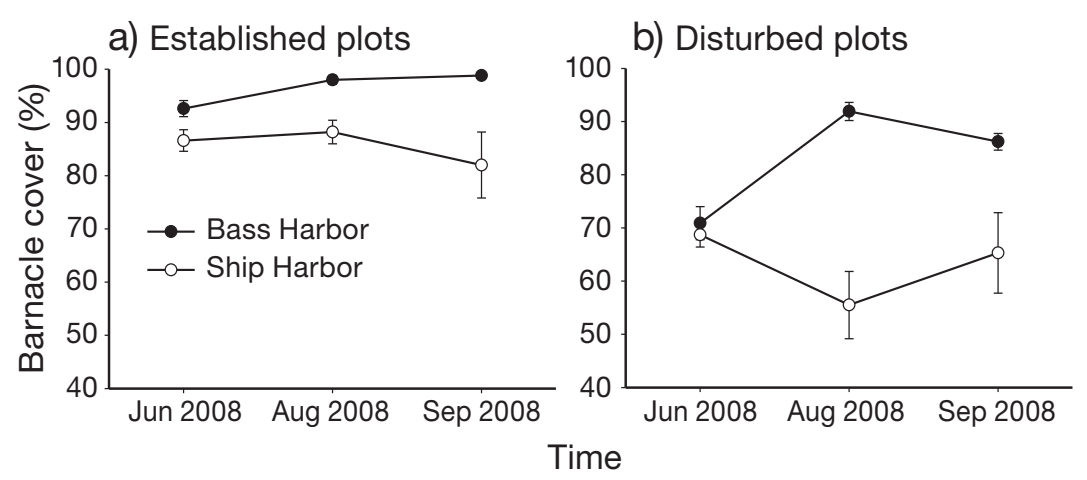

Fig. 1. Percent cover (mean $\pm \mathrm{SE}$ ) of barnacles in (a) established and (b) disturbed plots at Bass Harbor and Ship Harbor, Maine, USA. The interaction among site, plot type, and time was significant
Table 1. Repeated-measures ANOVA comparing barnacle cover over time in different plot types (established, disturbed) and at different sites (Bass Harbor and Ship Harbor). Barnacle cover was arcsin square-root transformed prior to analysis

\begin{tabular}{|lrrrr|}
\hline Source of variation & df & MS & \multicolumn{1}{c|}{$F$} & $\mathrm{p}$ \\
\hline Between subjects & & & & \\
$\quad$ Plot type (P) & 1 & 1.018 & 51.158 & $<0.001$ \\
Site (S) & 1 & 0.793 & 39.836 & $<0.001$ \\
$\mathrm{P} \times \mathrm{S}$ & 1 & 0.001 & 0.074 & 0.789 \\
Error & 16 & 0.020 & & \\
& & & & \\
Within subjects & & & & \\
Time (T) & 2 & 0.040 & 7.006 & 0.003 \\
$\mathrm{~T} \times \mathrm{P}$ & 2 & 0.002 & 0.273 & 0.763 \\
$\mathrm{~T} \times \mathrm{S}$ & 2 & 0.108 & 18.674 & $<0.001$ \\
$\mathrm{~T} \times \mathrm{P} \times \mathrm{S}$ & 2 & 0.035 & 6.066 & 0.006 \\
Error & 32 & 0.006 & & \\
\hline
\end{tabular}

cover reaching a low of $82 \pm 6 \%$ in September 2008 in established plots at $\mathrm{SH}$, cover recovered to June 2008 levels $(87 \pm 2 \%$ ) by June 2009 (91 $\pm 3 \%$ ).

Although declines in barnacle cover appeared to be seasonal, we observed differences in barnacle demographics that appear to persist for longer periods (Fig. 2). The percentage of 100 randomly selected barnacles in established plots that were newly recruited was $2.5 \times$ greater at the more heavily visited $\mathrm{SH}$ than at $\mathrm{BH}$. This estimate was conservative given that maximum barnacle basal area was $11 \%$ smaller at the heavily visited site (0.041 vs. $0.046 \mathrm{~cm}^{2}, \mathrm{SH}$ vs. BH).

During the human exclusion experiment, barnacle cover increased in all experimental plots except in uncaged plots at $\mathrm{SH}$ (i.e. the treatment that should have received the most trampling; Fig. 3). This led to 2 interesting 2-way interactions. (1) The increase at $\mathrm{SH}$ was less than the increase at $\mathrm{BH}$ (Fig. 3, Table 2: Time $\times$ Site interaction). (2) The increase was greater in caged than in uncaged plots (Fig. 3, Table 2: Time $\times$ Caging treatment interaction) . Importantly, the interactive effects of time and caging treatment varied with site $($ Time $\times$ Caging $\times$ Site interaction; $\left.F_{1,30}=6.079, \mathrm{p}=0.020\right)$. Thus, the differences in the effect of time between the 2 caging treatments depended upon site, with a greater difference at SH.

Surveys at low tide during the human exclusion experiment demonstrated striking differences in human visitation between sites but no differ- 


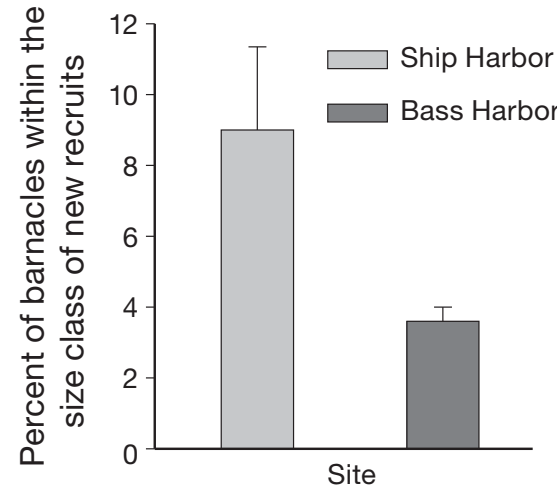

Fig. 2. Percent (mean $+\mathrm{SE})$ of barnacles falling below the estimated maximum size of new recruits in established plots. Barnacle sizes were measured in June 2008, after the major recruitment period and before the major period of natural trampling at Ship Harbor. New recruit size was estimated from disturbed plots
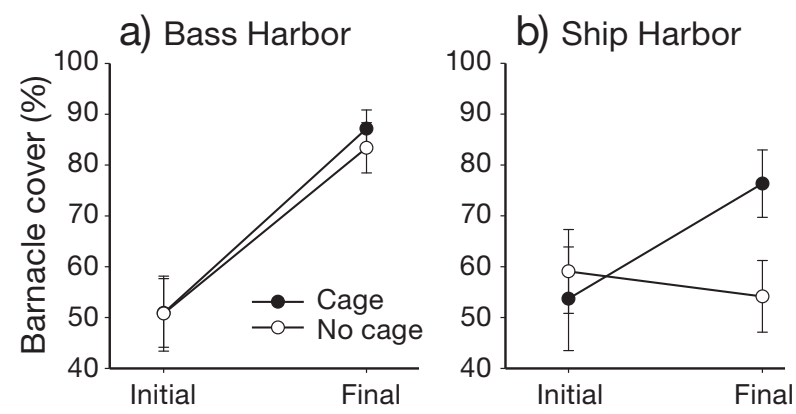

Fig. 3. Percent cover (mean $\pm \mathrm{SE}$ ) of barnacles at (a) Bass Harbor and (b) Ship Harbor during the human exclusion experiment. Cages excluded people but allowed access by dominant barnacle predators including dogwhelks and crabs. The interaction among site, caging treatment, and time was significant

Table 2. Repeated-measures ANOVA comparing barnacle cover over time in different caging treatments (caged, uncaged) and at different sites (Bass Harbor and Ship Harbor). Barnacle cover was arcsin square-root transformed prior to analysis

\begin{tabular}{|lrrrr|}
\hline Source of variation & df & MS & $F$ & $\mathrm{p}$ \\
\hline Between subjects & & & & \\
$\quad$ Caging treatment (C) & 1 & 0.063 & 0.717 & 0.404 \\
Site (S) & 1 & 0.145 & 1.661 & 0.207 \\
$\mathrm{C} \times \mathrm{S}$ & 1 & 0.021 & 0.628 & 0.628 \\
Error & 30 & 0.087 & & \\
& & & & \\
Within subjects & & & & \\
Time (T) & 1 & 1.115 & 85.439 & 0.001 \\
$\mathrm{~T} \times \mathrm{C}$ & 1 & 0.146 & 11.152 & 0.002 \\
$\mathrm{~T} \times \mathrm{S}$ & 1 & 0.405 & 31.013 & $<0.001$ \\
$\mathrm{~T} \times \mathrm{C} \times \mathrm{S}$ & 1 & 6.079 & 6.079 & 0.020 \\
Error & 30 & 0.013 & & \\
\hline
\end{tabular}

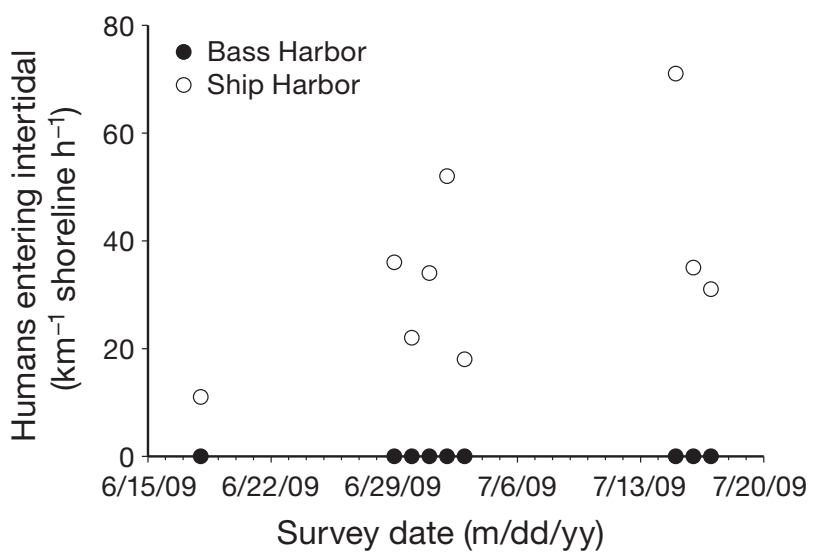

Fig. 4. Counts of humans entering the intertidal zone at Bass Harbor and Ship Harbor during simultaneous surveys. Surveys were started at 30 min before low tide and lasted $2 \mathrm{~h}$. Counts were adjusted to the surveyed length of the shore. During these surveys, we never saw other humans entering the intertidal zone at Bass Harbor

ence in predator abundance. For all 9 surveys, humans were never seen in the intertidal at $\mathrm{BH}$ but were often seen near experimental plots at SH (Fig. 4). In contrast, densities of the barnacle predator Nucella lapillus were not different between $\mathrm{BH}$ and SH on a site-wide basis $\left(F_{1,2}=0.030, \mathrm{p}=0.878\right)$. Within established barnacle monitoring plots, $N$. lapillus were absent at $\mathrm{SH}$ and only $1.2 \pm 0.7$ snails $\mathrm{m}^{-2}$ were observed at BH. Compared to the barnacle plots, Ascophyllum (32.2 \pm 11.2 and $52.2 \pm 20.5$ snails $\mathrm{m}^{-2}$ in BH and $\mathrm{SH}$, respectively) and Fucus plots (21.4 \pm 6.2 and $26.7 \pm 11.1$ snails $\mathrm{m}^{-2}$ in $\mathrm{BH}$ and $\mathrm{SH}$, respectively) had more abundant $N$. lapillus.

The slopes of the monitoring plots in the barnacle zone were not different between $\mathrm{SH}\left(10.85 \pm 1.50^{\circ}\right)$ and $\mathrm{BH}\left(8.03 \pm 0.81^{\circ} ; F_{1,18}=2.7, \mathrm{p}=0.116\right)$. However, these plots were $0.43 \mathrm{~m}$ higher at $\mathrm{SH}$ than at $\mathrm{BH}$ $(2.56 \pm 0.05$ and $2.13 \pm 0.07 \mathrm{~m}$ above mean low water, respectively; $F_{1,18}=21.7, \mathrm{p}<0.001$ ).

\section{DISCUSSION}

While previous disturbance to species-rich communities may shift species composition thereby altering community resistance to trampling (Hill \& Pickering 2009), our study suggests that previous disturbance can also enhance trampling effects in nearly monospecific stands. In barnacle communities, disturbance can create bare space that is seasonally colonized by new recruits. These previously disturbed areas appear more sensitive to trampling given that after the period of highest visitation, the difference in barnacle 
cover between the heavily visited site $(\mathrm{SH})$ and the pristine site $(\mathrm{BH})$ was greater in experimentally disturbed plots compared to unmanipulated established plots (Fig. 1). Although plots were higher at SH suggesting that elevation may have been an additional stressor at the more visited site, we argue that trampling was the major difference between these sites since barnacle cover only decreased in uncaged plots (i.e. trampling accessible) at the heavily visited site during the human exclusion experiment.

In monospecific stands, the consequences of trampling may depend on previous disturbance for at least 2 reasons. (1) New recruits to disturbed areas may be more susceptible to crushing by a given amount of trampling force than adults on a per-individual basis. Unlike small plants that survive better in trampled areas (Liddle 1991), barnacle recruits should be more vulnerable to trampling than adults because they are smaller and more susceptible to crushing, especially in disturbed areas dominated by similarly sized recruits (Simpson \& Hurlbert 1998). (2) Disturbed plots may be more susceptible to disturbance because their reduced cover (Bertness 1989) translates into greater per capita force from individual footsteps. Consistent with this hypothesis, initial barnacle cover prior to the major summertime trampling period was lower in our disturbed plots $(\sim 70 \%)$ where trampling had a greater effect than in unmanipulated plots ( 90\%). Similarly, 3 other studies that observed strong negative effects of trampling additions on barnacles were conducted in areas with low cover ( 70 and $20 \%$, Brosnan $1994 ; \sim 30 \%$, Ferreira \& Rosso 2009 ; $\sim 4.5$ barnacles per foot-sized quadrat, Povey \& Keough 1991).

Trampling effects on abundance or cover can be short-lived but there may be more subtle effects of trampling on population dynamics over longer periods (Rusterholz et al. 2009). In the short-term, high recruitment and growth may quickly replace lost individuals and biomass (Schiel \& Taylor 1999). Five months after trampling was applied to rocky shore plots of coralline algal mats, Povey \& Keough (1991) could not distinguish between heavily trampled and control areas. At our heavily visited site ( $\mathrm{SH})$, the decrease in barnacle cover during the summer of 2008 was no longer observed by June 2009 after the major period of barnacle recruitment. However, trampled areas were dominated by a greater proportion of new barnacle recruits. These recruits will not reproduce until the winter after recruitment and egg production can be an order of magnitude lower for barnacles in their first year compared to older individuals (Wethey 1985, Bertness et al. 1991). Thus, the combination of previous disturbance and trampling shifted the age structure towards younger individuals and could, therefore, strongly delay barnacle reproduction. Such an effect could be even stronger for species that take longer to reach reproductive maturity.

Trampling addition experiments can help assign causality, but only under the specific conditions in which trampling was applied. In other words, they come with several untested assumptions about the ecological relevance of the trampling. For example, although intertidal visitors vary in many ways, most trampling addition studies use a single individual (or weight class) wearing a single type of footwear and walking with a 'normal stride' to apply the trampling (Schiel \& Taylor 1999, Smith \& Murray 2005, Casu et al. 2006). Also, trampling is typically applied in discrete pulses such as during a single low tide (Schiel \& Taylor 1999) or on a monthly basis (Smith \& Murray 2005). Presumably, experimental trampling additions occur relatively quickly compared to natural trampling that may occur across the entire low tide. We suspect that these factors (e.g. weight, footwear, and stride of trampler; frequency and duration of trampling) could largely determine the outcome of trampling on intertidal communities. Thus, an advantage of our experiments was that we avoided these assumptions at our sites by allowing natural trampling.

Clearly, stressors do not act on communities in isolation and the consequences of any one disturbance will likely depend on others, thereby leading to 'ecological surprises' (Darling \& Cote 2008). In this study, experimental scraping representing natural disturbance interacted with sites with extremely different levels of visitation to create short-term reductions in barnacle cover that were greater than would be predicted from studying these disturbances in isolation. Future studies should (1) determine the ecological relevance of trampling addition experiments, especially with regards to natural trampling, and (2) examine the interaction between trampling and previous disturbance at additional sites to explore the generality of these findings. Examining such multiple stressor effects is becoming increasingly important for ecosystem-based management as the frequency of co-occurring and sequential disturbances increases with human population growth and climate change (Emanuel 1987, Halpern et al. 2008).

Acknowledgements. D. Manski facilitated our work in Acadia for over 5 yr. B. Connery's efficiency with respect to logistics in Acadia was amazing. Several volunteers allowed us to conduct simultaneous paired surveys. Bar Harbor's Morning Glory Bakery kept the team well-fed and happy. T. Jones 
encouraged critical thinking that led to revelations. J. McKenna introduced 2 of the coauthors. Support for this project was provided by an L. L. Bean Fellowship and an NSF grant (OCE-0825846) to J.D.L. This is Contribution No. 12 of the Coastal and Marine Institute Laboratory, San Diego State University.

\section{LITERATURE CITED}

Altieri AH, Trussel GC, Ewanchuk PJ, Bernatchez G, Bracken MES (2009) Consumers control diversity and functioning of a natural marine ecosystem. PLoS One 4:e4291

> Beauchamp KA, Gowing MM (1982) A quantitative assessment of human trampling effects on a rocky intertidal community. Mar Environ Res 7:279-293

Bertness MD (1989) Intraspecific competition and facilitation in a northern acorn barnacle population. Ecology 70: 257-268

> Bertness MD, Gaines SD, Bermudez D, Sanford E (1991) Extreme spatial variation in the growth and reproductive output of the acorn barnacle Semibalanus balanoides. Mar Ecol Prog Ser 75:91-100

Brosnan DM, Crumrine LL (1994) Effects of human trampling on marine rocky shore communities. J Exp Mar Biol Ecol 177:79-97

> Brown PJ, Taylor RB (1999) Effects of trampling by humans on animals inhabiting coralline algal turf in the rocky intertidal. J Exp Mar Biol Ecol 235:45-53

> Castilla JC, Duran LR (1985) Human exclusion from the rocky intertidal zone of central Chile: the effects on Concholepas concholepas (Gastropoda). Oikos 45:391-399

> Casu D, Ceccherelli G, Curini-Galletti M, Castelli A (2006) Human exclusion from rocky shores in a Mediterranean marine protected area (mpa): an opportunity to investigate the effects of trampling. Mar Environ Res 62:15-32

Connell JH (1978) Diversity in tropical rain forests and coral reefs. Science 199:1302-1310

Crain CM, Kroeker K, Halpern BS (2008) Interactive and cumulative effects of multiple human stressors in marine systems. Ecol Lett 11:1304-1315

> Darling ES, Cote IM (2008) Quantifying the evidence for ecological synergies. Ecol Lett 11:1278-1286

Emanuel KA (1987) The dependence of hurricane intensity on climate. Nature 326:483-485

Engle JM (2006) Unified monitoring protocols for the multiagency rocky intertidal network. OCS Study, Minerals Management Service 0602

Ferreira MN, Rosso S (2009) Effects of human trampling on a rocky shore fauna on the Sao Paulo coast, Southeastern Brazil. Braz J Biol 69:993-999

Gilman RA, Chapman CA (1988) Bedrock geology of Mount Desert Island. Bulletin 38, Maine Geological Survey, Augusta, ME

> Godefroid S, Massant W, Weyembergh G, Koedam N (2003) Impact of fencing on the recovery of the ground flora on heavily eroded slopes of a deciduous forest. Environ Manag 32:62-76

Goldstein DS (1992) Long term ecological stability within a disturbed intertidal region. BSc thesis, University of California, Santa Cruz

Halpern BS, McLeod KL, Rosenberg AA, Crowder LB (2008) Managing for cumulative impacts in ecosystem-based management through ocean zoning. Ocean Coast Manag 51:203-211
Hart SA, Chen HYH (2008) Fire, logging, and overstory affect understory abundance, diversity, and composition in boreal forest. Ecol Monogr 78:123-140

Heaven CS, Scrosati RA (2008) Benthic community composition across gradients of intertidal elevation, wave exposure, and ice scour in Atlantic Canada. Mar Ecol Prog Ser 369:13-23

Hill R, Pickering C (2009) Differences in resistance of three subtropical vegetation types to experimental trampling. J Environ Manage 90:1305-1312

Hughes TP, Connell JH (1999) Multiple stressors on coral reefs: a long-term perspective. Limnol Oceanogr 44: 932-940

Hughes TP, Reed DC, Boyle MJ (1987) Herbivory on coral reefs: community structure following mass mortalities of sea urchins. J Exp Mar Biol Ecol 113:39-59

Jenkins C, Haas ME, Olson A, Ruesink JL (2002) Impacts of trampling on a rocky shoreline of San Juan Island, Washington, USA. Nat Areas J 22:260-269

Keough MJ, Quinn GP (1991) Causality and the choice of measurements for detecting human impacts in marine environments. Aust J Mar Freshw Res 42:539-554

Lessios HA (1988) Mass mortality of Diadema antillarum in the Caribbean: What have we learned? Annu Rev Ecol Syst 19:371-393

Liddle MJ (1991) Recreation ecology: effects of trampling on plants and corals. Trends Ecol Evol 6:13-17

Long JD, Mitchell BR (2010) Northeast Temperate Network long-term rocky intertidal monitoring protocol, National Park Service. Northeast Temperate Network

Lubchenco J (1983) Littorina and Fucus: effects of herbivores, substratum heterogeneity, and plant escapes during succession. Ecology 64:1116-1123

Martone RG, Wasson K (2008) Impacts and interactions of multiple human perturbations in a California salt marsh. Oecologia 158:151-163

Menge BA (1976) Organization of the New England rocky intertidal community: role of predation, competition, and environmental heterogeneity. Ecol Monogr 46:355-393

Menge BA (1991) Relative importance of recruitment and other causes of variation in rocky intertidal community structure. J Exp Mar Biol Ecol 146:69-100

> Menge BA, Sutherland JP (1976) Species diversity gradients: synthesis of the roles of predation, competition, and temporal heterogeneity. Am Nat 110:351-369

> Menge BA, Sutherland JP (1987) Community regulation: variation in disturbance, competition, and predation in relation to environmental stress and recruitment. Am Nat 130:730-757

Micheli F, Peterson CH, Mullineaux LS, Fisher CR and others (2002) Predation structures communities at deep-sea hydrothermal vents. Ecol Monogr 72:365-382

Murray SN, Ambrose RF, Dethier MN (2006) Monitoring rocky shores. University of California Press, Berkeley

Navarrete SA, Castilla JC (2003) Experimental determination of predation intensity in an intertidal predator guild: dominant versus subordinate prey. Oikos 100:251-262

> Pentcheff ND (1991) Resistance to crushing from waveborne debris in the barnacle Balanus glandula. Mar Biol 110:399-408

> Povey A, Keough MJ (1991) Effects of trampling on plant and animal populations on rocky shores. Oikos 61: 355-368

> Raimondi PT (1988) Rock type affects settlement, recruitment, and zonation of the barnacle Chthamalus anisopo- 
ma Pilsbury. J Exp Mar Biol Ecol 123:253-267

Rusterholz HP, Kissling M, Baur B (2009) Disturbances by human trampling alter the performance, sexual reproduction and genetic diversity in a clonal woodland herb. Perspect Plant Ecol Evol Syst 11:17-29

Schiel DR, Taylor DI (1999) Effects of trampling on a rocky intertidal algal assemblage in southern New Zealand. J Exp Mar Biol Ecol 235:213-235

Schoch GC, Dethier MN (1996) Scaling up: the statistical linkage between organismal abundance and geomorphology on rocky intertidal shorelines. J Exp Mar Biol Ecol 201:37-72

Simpson EP, Hurlbert SH (1998) Salinity effects on the growth, mortality and shell strength of Balanus amphitrite from the Salton Sea, California. Hydrobiologia 381: 179-190

Smith JR, Murray SN (2005) The effects of experimental bait collection and trampling on a Mytilus californianus mussel bed in Southern California. Mar Biol 147:699-706

Sousa WP (1979) Disturbance in marine intertidal boulder fields: the nonequilibrium maintenance of species diversity. Ecology 60:1225-1239

Van De Werfhorst LC, Pearse JS (2007) Trampling in the

Editorial responsibility: Antony Underwood, Sydney, Australia rocky intertidal of Central California: a follow-up study. Bull Mar Sci 81:245-254

- Vaselli S, Bertocci I, Maggi E, Benedetti-Cecchi L (2008) Assessing the consequences of sea level rise: effects of changes in the slope of the substratum on sessile assemblages of rocky seashores. Mar Ecol Prog Ser 368:9-22

> Vinueza LR, Branch GM, Branch ML, Bustamante RH (2006) Top-down herbivory and bottom-up El Nino on Galapagos rocky-shore communities. Ecol Monogr 76:111-131

$>$ Warwick SI, Briggs D (1978) Genecology of lawn weeds 2. Evidence for disruptive selection in Poa annua in a mosaic environment of bowling green lawns and flower beds. New Phytol 81:725-737

Wethey DS (1985) Catastrophe, extinction, and species diversity: a rocky intertidal example. Ecology 66: 445-456

Yorks TP, West NE, Mueller RJ, Warren SD (1997) Toleration of traffic by vegetation: life form conclusions and summary extracts from a comprehensive data base. Environ Manag 21:121-131

Zedler J (1978) Public use effects in the Cabrillo National Monument intertidal zone. Project report for the US Department of Interior National Park Service

Submitted: February 9, 2011; Accepted: July 7, 2011

Proofs received from author(s): September 5, 2011 